\title{
Chinese soccer association super league, 2012-2017: key performance indicators in balance games
}

\author{
Changjing Zhou $(\mathbb{D}$, Shaoliang Zhang $\mathbb{D}$, Alberto Lorenzo Calvo $(\mathbb{D})$ and Yixiong Cui $(\mathbb{1}$
}

Faculty of Physical Activity and Sport Sciences (INEF), Polytechnic University of Madrid, Madrid, Spain

\begin{abstract}
The aim of the present study was to identify the game-related statistics which discriminate between winning, drawing and losing teams in Chinese Soccer Association Super League. The sample included 1056 balance games from the 2012-2017 Chinese Soccer Association Super League. Physical and technical game-related statistics were gathered. A one-way analysis of variance and discriminant analysis of data was done. The results showed that winning teams were significantly higher for the following game statistics: shots, shots on target, 50-50 challenge won, offsides, sprinting distance, sprinting effort, sprinting distance in ball possession and high-speed-running distance in ball possession. Losing teams had significantly higher averages in the variable crosses, passes, forward passes, sprinting distance out of ball possession and high-speed-running distance out of ball possession. Discriminant analysis concluded the following: the variables that discriminate between winning, drawing and losing teams were the shots on target, sprinting distance in ball possession, quality of opposition, passes and forward passes. Coaches and players should be aware of these different profiles in order to design and evaluate practices and competitions for their teams.
\end{abstract}

\section{ARTICLE HISTORY}

Received 7 May 2018

Accepted 5 August 2018

\section{KEYWORDS}

Key performance indicator; Chinese soccer; discriminant analysis

\section{Introduction}

Performance indicators in sport can be defined as the selection and combination of variables that define some aspects of performance (Hughes \& Bartlett, 2002). These indicators constitute an ideal profile that can be used to predict future behaviour in a given sporting activity (O'Donoghue, 2005). In the context of soccer, the evolution of performance indicators in successive years is an opportunity to recognise the development of soccer matches.

Lago et al. (2010) found that the variable total shots, shots on target, crosses, crosses against, ball possession and match location had the greatest discriminatory power between winners and losers with regard to matches played in the Spanish league. Castellano, Casamichana, and Lago (2012) also found that the variable total shots, shots on target and ball possession had the greatest discriminatory power with regard to matches played in three World Cups (2002, 2006, 2010). Harrop and Nevill (2014)

CONTACT Changjing Zhou zhouchangjing1@gmail.com E Faculty of Physical Activity and Sport Sciences (INEF), Polytechnic University of Madrid, Spain

(C) 2018 Cardiff Metropolitan University 
found that perform fewer passes but complete more successful passes and shots to be successful; however, their result showed that no significant differences for the mean number of total shots or shots on target when a sampled team was successful or unsuccessful.

Several contextual factors influence physical and technical match performance in soccer players, including match location and opposition quality (Aquino, Martins, Vieira, \& Menezes, 2017; Bradley, Lago-Peñas, Rey, \& Sampaio, 2014; Lago \& Martín, 2007; Liu, Hopkins, \& Gomez, 2016; Taylor, Mellalieu, James, \& Barter, 2010; Taylor, Mellalieu, James, \& Shearer, 2008). It has been noted that a match location may incite adaptations to the team's playing style, but also to the decision-making of individual players (Kite \& Nevill, 2017). Thus, home advantage can play an important role in determining the outcome of a match (Lago-Peñas, Lago-Ballesteros, \& Rey, 2011). When considering opponent's quality, the match location has different effects on match performance. Game location had only trivial effects on the winning probability for upper ranked teams when playing against upper ranked opponents, but had positive effects for upper ranked teams when facing lower ranked teams and for lower ranked teams when facing oppositions of whatever strengths (Mao, Peng, Liu, \& Gómez, 2016). Lago-Penas and Lago-Ballesteros (2011) also found that stronger teams do not have the same advantages when they play at home, as occurs with weak opponents. In previous studies, the general breakdown of all teams into strong and weak teams does not really show the opponent's strength or weakness relative to itself. Difference between end-ofseason rankings of the competing teams can truly reflect the strength gap between the two teams (Bradley et al., 2014).

The literature has previously demonstrated the likely association between physical performance and skill-related performance (Carling \& Dupont, 2011), and physical performance directly interfering in team dynamics and tactical performance (Moura et al., 2013). The result of previous studies (Aquino et al., 2017; Faude, Koch, \& Meyer, 2012) showed that high-intensity actions are related to the outcome of the match. Gómez and his colleagues have highlighted the importance of physical conditioning in the process of winning basketball match (Gómez, Gasperi, \& Lupo, 2016) and water polo (Gómez, Serna, Lupo, \& Sampaio, 2016) balance games. However, the previous study indicated that overall technical and tactical effectiveness of the team rather than high levels of physical performance are more important in determining success in soccer (Di Salvo, Gregson, Atkinson, Tordoff, \& Drust, 2009). In summary, the technical and physical indicators that affect the outcome of the soccer match are not clear, and few studies have been devoted to simultaneously study the effects of technical and physical indicators on match outcomes.

The performance analysis in soccer is currently Europe-centred (Mao et al., 2016), and most of the scientific research has been focused on describing the technical-tactical and physical performance of European top-league teams and players. Although insightful information is provided for coaches and researchers, there is scarce investigation for Asian soccer, which is comparatively less developed and requires more scientific feedback. Chinese Soccer Association Super League (CSL) would serve as an ideal model as it has attracted recently a great number of high-level players and coaches to work for the teams, bringing them the latest training program and tactical concepts. Along with that, the recent advanced player-tracking technology has provided a more 
comprehensive match report. Therefore, it is of great interest to understand the CSL team and players' match-play patterns.

The aim of the present study was to identify the match statistics (technical and physical variables) and contextual factors (match location and opposition quality) which best discriminated between winning, drawing and losing teams in Chinese soccer association super league.

\section{Method}

\subsection{Sample, data resource and variables}

Chinese Soccer Association Super League is the highest level of professional soccer match in China, which starts in March (spring in China) and ends in November (winter) every season. In each season, every team plays against twice with different opponents for home and away match, respectively. There are 240 matches that were completed by 16 teams in the each season (each team played 30 matches in the league). The end-of-season rank is determined by the final accumulated points (win for 3 points, draw for 1 , loss for 0 ). A total of 1430 matches were selected as the sample of the current study from 2012 to 2017 seasons in the Chinese Soccer Association Super League.

Teams' tracking data of 1430 matches were collected by AMISCO (Amisco, Nice, France) tracking system. The reliability and validity of the system in measuring player movement has been evaluated (Zubillaga, Gorospe, Mendo, \& Villaseñor, 2007).

\subsection{Procedure and statistical analysis}

Gómez, DelaSerna, Lupo, and Sampaio (2014) pointed out that match performance should be analysed in relation to specific margin of victory. The balance matches (close matches) represent the highest level of performance between confronting teams in an open outcome. However, due to the emergence of red cards, the decrease in the player number of one team will cause the imbalance of the game. Therefore, in order to differentiate balanced matches and unbalanced matches, firstly we ruled out the matches where there emerged red card(s) during the course of the match, leaving 1218 matches selected. Then a two-step cluster analysis with Euclidean as the distances measure and Schwartz's Bayesian criterion was carried out to classify final goal differences into balance matches and unbalanced matches (Liu, Gomez, Lago-Penas, \& Sampaio, 2015). Results identified 1 cluster of 162 (13.3\%) matches (unbalanced matches with a goal difference of more than 2 goals $(3.51 \pm 0.79$, ranged from 3 to 7 , $n=324$ observations) and another cluster of 1056 (86.7\%) matches (balance matches with a difference of less than and equal to 2 goals $(0.88 \pm 0.73$, ranged from 0 to 2 , $n=2112$ observations), which finally limited to the 1056 matches that were proceeded for further statistical analysis. The quality of the clustering model was measured by the average silhouette coefficient, which is a measure of both cohesion and separation. It was assessed as follows: $-1.0-0.2$, poor model, $0.2-0.5$, moderate-to-fair model; $>0.5$, very good model. The average silhouette coefficient in this research is 0.7 . 
In line with previous related literature (Carling, Bradley, Mccall, \& Dupont, 2016; Mao et al., 2016; Yang, Leicht, Lago, \& Gómez, 2018), 16 technical performance-related parameters and 11 physical performance-related parameters were chosen as dependent variables in the analysis. The grouping and definition of these variables are in Table 1. Predictor variables in percent units (possession, possession in opponent half, pass accuracy, forward pass accuracy, 50-50 challenge won) and physical variables of all the match (total distance, sprinting distance, sprinting effort, high-speed-running distance, high-speed-running effort) were analysed as original values.

Team ranking was the final position in the end-of-season ranking of each team. Quality of opposition was the difference between end-of-season rankings of the competing teams (quality of opposition: QO) (Bradley et al., 2014)

Other variables related to technical, physical performance were analysed as values adjusted to per $50 \%$ of ball possession of the own team (Liu et al., 2015; Mao et al., 2016), which is as follows:

Table 1. Selected technical and physical performance-related parameters.

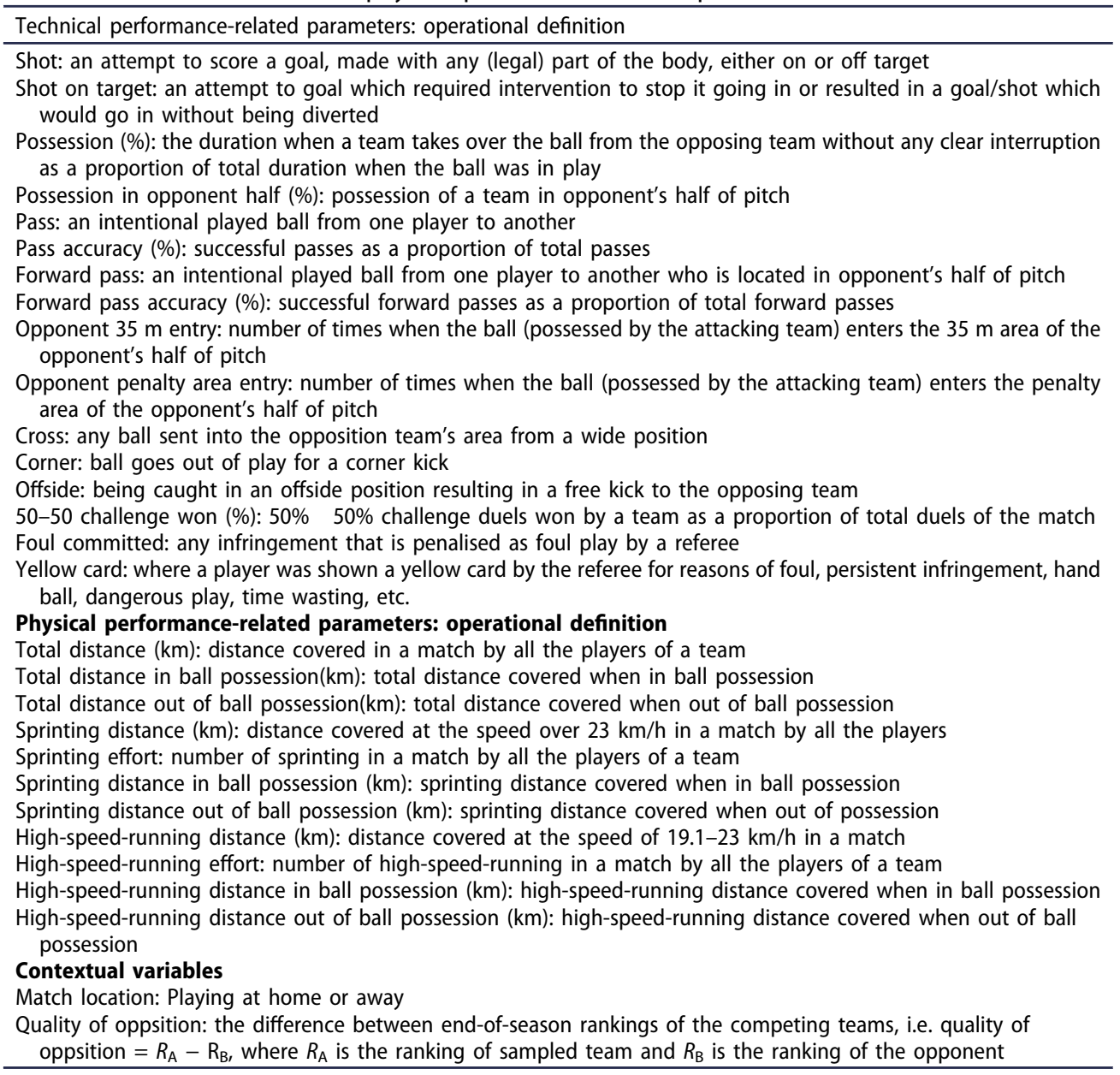




$$
V_{\text {ajstd }}=\left(V_{\text {original }} / \mathrm{P}_{\text {team }}\right) * 50 \%
$$

where $V=$ value of a variable; $P_{\text {team }}=$ possession of the own team.

While other variables related to defending were analysed as values adjusted to per $50 \%$ of ball possession of the opposition team (Liu et al., 2015; Mao et al., 2016), which is,

$$
V_{\text {ajstd }}=\left(V_{\text {original }} / \mathrm{P}_{\text {opposition }}\right) \times 50 \%
$$

where $V=$ value of a variable; $P_{\text {opposition }}=$ possession of the opposition team.

A one-way analysis of variance (ANOVA) was carried out to identify univariate differences between the game-related statistics between winning, drawing and losing teams. Afterwards, a discriminant analysis was performed in order to identify which variables best discriminated between winning, drawing and losing teams (Castellano et al., 2012; Lago-Peñas et al., 2010; Ntoumanis, 2001). This was achieved by calculating the structural coefficients (SC), with values $>|0.30|$ being regarded as significant (Tabachnick, Fidell, \& Osterlind, 2001).

\section{Result}

The ANOVA results of the game-related statistics for winning, drawing and losing teams are presented in Table 2 . There were some variables significantly higher for winning teams than drawing and losing teams: shots $(F=10.84, P<0.01)$, shots on target $(F=79.88, P<0.01), 50-50$ challenge won $(F=12.06, P<0.01)$, offsides $(F=10.00, P<0.01)$, sprinting distance $(F=5.74, P<0.01)$, sprinting effort $(F=4.63, P=0.01)$, sprinting distance in ball possession $(F=69.31, P<0.01)$ and high-speed-running distance in ball possession $(F=12.80, P<0.01)$. However, crosses from winning teams $(F=14.35, P<0.01)$ were lower than those of both drawing and losing teams. There were some variables significantly higher for losing teams than winning and drawing teams: passes $(F=9.38, P<0.01)$, forward passes $(F=13.91, P<0.01)$, sprinting distance out of ball possession $(F=30.22, P<0.01)$ and high-speed-running distance out of ball possession $(F=13.59, P<0.01)$.

The results of the multivariate analysis are presented in Table 3. Both discriminant functions obtained were significant $(P<0.01)$. In first discriminant function, the variables that had a higher discriminatory power were the shots on target ( $\mathrm{SC}=-0.33)$, sprinting distance in ball possession ( $\mathrm{SC}=-0.32$ ), quality of opposition $(\mathrm{SC}=0.40)$, and in second discriminant function the variables that had a higher discriminatory power were the shots on target $(S C=0.49)$, passes $(S C=0.40)$ and forward passes $(\mathrm{SC}=0.34)$.

\section{Discussion}

The aim of this study was to identify the performance indicators that best discriminated between winning, drawing and losing teams in CSL from 2012 to 2017.

The results of the ANOVA analysis identified 13 variables that differed between winning, drawing and losing teams (Table 2), while in the subsequent multivariate 


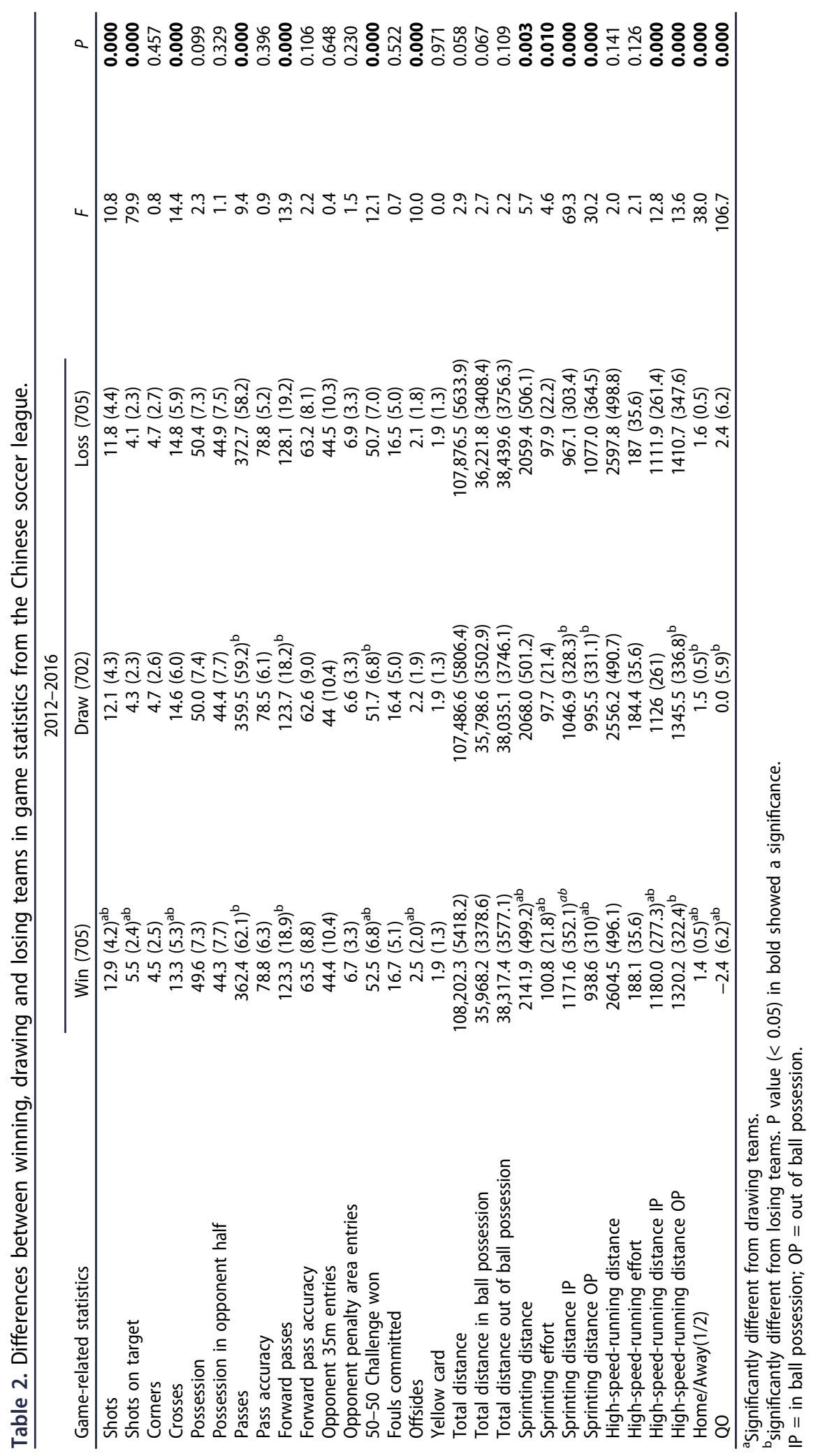


Table 3. Structure coefficients (SC) of technical and physical performance.

\begin{tabular}{|c|c|c|}
\hline \multirow[b]{2}{*}{ Game-related statistics } & \multicolumn{2}{|c|}{ Function } \\
\hline & 1 & 2 \\
\hline Shots & -0.13 & 0.09 \\
\hline Shots on target & $-0.33^{*}$ & $0.49^{*}$ \\
\hline Corners & 0.03 & -0.07 \\
\hline Crosses & 0.14 & -0.19 \\
\hline Possession & 0.06 & 0.02 \\
\hline Possession in opponent half & 0.04 & 0.08 \\
\hline Passes & 0.08 & $0.40^{*}$ \\
\hline Passes accuracy & -0.01 & 0.18 \\
\hline Forward passes & 0.12 & $0.34^{*}$ \\
\hline Forward pass accuracy & -0.03 & 0.25 \\
\hline Opponent $35 \mathrm{~m}$ entry & 0.00 & 0.12 \\
\hline Opponent enalty area entries & 0.03 & 0.15 \\
\hline 50-50 Challenges won & -0.13 & -0.10 \\
\hline Fouls committed & -0.03 & 0.09 \\
\hline Yellow cards & -0.12 & 0.09 \\
\hline Offsides & -0.01 & -0.02 \\
\hline Total distance & -0.03 & 0.26 \\
\hline Total distance in ball possession & 0.03 & 0.25 \\
\hline Total distance out of ball possession & 0.01 & 0.26 \\
\hline Sprinting distance & -0.09 & 0.14 \\
\hline Sprinting effort & -0.07 & 0.18 \\
\hline Sprinting distance in ball possession & $-0.32^{*}$ & 0.06 \\
\hline Sprinting distance out of ball possession & 0.21 & 0.19 \\
\hline High-speed-running distance & -0.01 & 0.24 \\
\hline High-speed-running effort & -0.02 & 0.24 \\
\hline High-speed-running distance in ball possession & -0.14 & 0.15 \\
\hline High-speed-running distance out of ball possession & 0.14 & 0.22 \\
\hline Home/away(1/2) & 0.24 & 0.10 \\
\hline Quality of oppsition & $0.40^{*}$ & 0.16 \\
\hline Eigenvalue & 0.63 & 0.03 \\
\hline Wilks' Lambda & 0.60 & 0.97 \\
\hline Canonical correlation & 0.62 & 0.17 \\
\hline Chi-square & 1077.76 & 61.36 \\
\hline df & 58 & 28 \\
\hline Significance & 0.000 & 0.000 \\
\hline$\%$ of Variance & 95.46 & 4.54 \\
\hline
\end{tabular}

*SC discriminant value $\geq|0.30|$.

analysis, only five variables were found to be discriminate teams in relation to their performance (Table 3).

The present study indicates that winning teams have more shots and shots on target than losing and drawing teams, but shots on target best discriminate team performance. Our findings are in line with the study that showed that shot on target may have substantially positive effects on the probability of winning (Mao et al., 2016). Some researchers also found that shots on target had the greatest discriminatory power with regard to matches played in three World Cups (2002, 2006, 2010)(Castellano et al., 2012), in the Spanish league (Lago-Peñas et al., 2010) and in the Italy league (Rampinini, Impellizzeri, Castagna, Coutts, \& Wisloff, 2009). This is also consistent with the findings of Szwarc (2004), who reported that winning teams made only four more shots than less successful teams, but the effectiveness of their shots was three-fold greater. In addition, this result is in accordance with previous studies that showed that the quality of shots rather than the quantity of that in soccer matches determines the 
game result (Liu et al., 2015, 2016; Yue, Broich, \& Mester, 2014). Considering the high importance of shots on target, training should be more focused on shooting accuracy.

Concerning the performance indicators related to passes, there were differences between winning, losing and drawing teams in the following variables: passes, crosses and forward passes. Firstly, losing teams make more passes, crosses and forward passes than winning and drawing teams, but there is no difference in forward pass accuracy. Our results are in line with the finding that cross showed negative between- and withinteam effects on probability of winning (Liu et al., 2016). This finding demonstrates that players from losing teams employed more strategies of offence (forward passes) and sending the ball from a wide position into the opponent's area through more crosses, but getting less $50-50$ challenges win indicates that efficiency of cross is low. This is probably because weak teams are usually less developed and worse prepared in the offensive organisation (Liu et al., 2016).

The results from the present study indicate that winning teams have more 50-50 challenges win and offsides than losing and drawing teams. The research of Liu et al. (2016) also indicated that teams winning more aerial duels tended to win more games. Previous observations on offside showed contradictory conclusions: one showed that there were differences among winning, drawing and losing teams (Lago-Peñas et al., 2010), and another study showed that offside had a clear positive within-team relationship with probability of winning (Liu et al., 2016), while others showed that there were no differences (Castellano et al., 2012; Lago-Peñas et al., 2011). Penetrative passes that could produce shot opportunities that are close to the goal-scoring area are of great importance in attacking, while this type of pass is normally associated with offside (Liu et al., 2016). These results of the present study could suggest that the players of winning teams are more aggressive in the duels process and in the offence process.

The previous studies often postulated that a high-level of match running performance is important for achieving success in professional soccer teams (Hoppe, Slomka, Baumgart, Weber, \& Freiwald, 2015). In addition, previous studies (Aquino et al., 2017; Faude et al., 2012) showed that high-intensity actions are related to match outcome. The present results show that winning teams have more sprinting distance and high-speed-running distance when they are in ball possession than losing teams, but when they are out of ball possession, they covered less sprinting and high-speed-running distance. However, only sprinting distance in ball possession $(>23 \mathrm{~km} / \mathrm{h})$ is a vital variable in discriminating winning, drawing and losing. Hoppe et al. (2015) reported total distance in ball possession as the strongest predictor of point accumulation across a season in German Bundesliga soccer teams. Another study also showed that higher-ranked teams from the Italian Series A League run greater distances in total and recorded more high-speed running (running speed $>14 \mathrm{~km} / \mathrm{h}$ ) with the ball possession than lower-ranked teams (Rampinini et al., 2009). However, in the present research, total distance in ball possession is not a variable in discriminating winning, drawing and losing.

Comparisons across studies are difficult due to differences in the technology used to quantify player movement and the speed thresholds used to define movement categories (Carling, Bloomfield, Nelsen, \& Reilly, 2008). Our research indicated that teams of CSL increase more sprinting distance with ball possession to win the match. Although there is no relevant research, compared with European soccer teams (take La Liga for example), teams from CSL have less passing number ( 365 vs. 400) (Liu et al., 2016), indicating 
that the ability to control the game is significantly lower than that of European teams and the attack of CSL teams is more dependent on direct play than on possession play, and this puts high demands on the sprinting ability of the players. If a team has stronger sprint run ability on offence, they are more likely to win the game. The previous study and the present study suggested that the match running performance alone is not a key indicator for achieving success. The previous literature also demonstrated the likely association between physical performance and skill-related performance (Carling \& Dupont, 2011), and physical performance directly interfering in team dynamics and tactical performance (Moura et al., 2013). The results of the present research suggested that combining the technical and physical indicators for analysis can help more fully understand the match performance. These results enhance the importance of player sprinting ability in the attacking process; coaches could improve the sprinting performance of players when their team controls the ball through purposeful training. For example, increase the passing training and shoot accuracy practice in the case of players' rapid movement. In the second discriminant function, the variables that had a higher discriminatory power were the shots on target $(\mathrm{SC}=0.49)$, passes $(\mathrm{SC}=0.40)$ and forward passes $(\mathrm{SC}=0.34)$. Previous studies have concluded that shots on target and passing are mainly evident between winning and losing teams (Grant, Williams, Reilly, \& Borrie, 1999). Additionally, another study found that possession time and passing predicted aggregated team success in domestic league play while both variables were poor predictors at the individual match level considering team quality and home advantage (Collet, 2013). In the present research, regardless of match location and quality of opposition, more shots on target and less passes and forward passes could lead a successful match which means that more directly offence maybe a useful method to win the match. Harrop and Nevill (2014) suggested that the best tactical approach may be directly related to the skill level of the team. If the skill level of the team is insufficient to maintain meaningful possession, a "direct" style of play may be a better tactic to adopt (Kite \& Nevill, 2017). If the objective of playing direct is to move the ball into a shooting position as quickly as possible, the team is also more likely to be successful with more shots on target (Kite \& Nevill, 2017).

Match location is one of the variables that better differentiate winning, losing and drawing teams in Spanish La Liga (Lago-Peñas et al., 2010). In the present study, match location is not a variable that differences between the winning and the losing teams. However, the quality of opposition is a variable that differs between the winning, drawing and the losing matches. It shows that the quality of opposition is the more important index that affects match outcome when both of the home advantage and the opponent's quality are taken into account.

\section{Conclusion}

In summary, this study has analysed match statistics related to the technical and physical of winning, drawing and losing teams in CSL. It has sought to identify the performance indicators that best discriminate among winning, drawing and losing teams. The variables that better differentiate winning, drawing and losing teams in a global way were the following: shots on target, sprinting distance in ball possession, quality of opposition, passes and forward passes. For teams in CSL to achieve more success, they should attempt 
fewer passes to move the ball into a shooting position as quickly as possible, then the team is also more likely to be successful if they have more shots on target. The results may be of use to coaches in terms of designing their training programmes.

\section{Disclosure statement}

No potential conflict of interest was reported by the authors.

\section{Funding}

The work was supported by the China Scholarship Council (CSC) from the Ministry of Education of P.R. China, under grant number 201609110105.

\section{ORCID}

Changjing Zhou (D) http://orcid.org/0000-0002-5666-9120

Shaoliang Zhang (D) http://orcid.org/0000-0002-0543-7135

Alberto Lorenzo Calvo (iD http://orcid.org/0000-0002-4633-6701

Yixiong Cui (D) http://orcid.org/0000-0002-1755-9631

\section{References}

Aquino, R., Martins, G. H. M., Vieira, L. H. P., \& Menezes, R. P. (2017). Influence of match location, quality of opponents, and match status on movement patterns in Brazilian professional football players. The Journal of Strength \& Conditioning Research, 31(8), 2155-2161.

Bradley, P. S., Lago-Peñas, C., Rey, E., \& Sampaio, J. (2014). The influence of situational variables on ball possession in the english premier league. Journal of Sports Sciences, 32(20), $1867-1873$.

Carling, C., Bloomfield, J., Nelsen, L., \& Reilly, T. (2008). The role of motion analysis in elite soccer: Contemporary performance measurement techniques and work rate data. Sports Medicine, 38(10), 839-862. Retrieved from http://www.ncbi.nlm.nih.gov/pubmed/18803436

Carling, C., Bradley, P., Mccall, A., \& Dupont, G. (2016). Match-to-match variability in highspeed running activity in a professional soccer team. Journal of Sports Sciences, 34(24), 22152223.

Carling, C., \& Dupont, G. (2011). Are declines in physical performance associated with a reduction in skill-related performance during professional soccer match-play? Journal of Sports Sciences, 29(1), 63-71. Retrieved from http://www.ncbi.nlm.nih.gov/pubmed/ 21077004.

Castellano, J., Casamichana, D., \& Lago, C. (2012). The use of match statistics that discriminate between successful and unsuccessful soccer teams. Journal of Human Kinetics, 31, 137-147.

Collet, C. (2013). The possession game? A comparative analysis of ball retention and team success in European and international football, 2007-2010. Journal of Sports Sciences, 31(2), 123-136.

Di Salvo, V., Gregson, W., Atkinson, G., Tordoff, P., \& Drust, B. (2009). Analysis of high intensity activity in premier league soccer. International Journal of Sports Medicine, 30(03), 205-212.

Faude, O., Koch, T., \& Meyer, T. (2012). Straight sprinting is the most frequent action in goal situations in professional football. Journal of Sports Sciences, 30(7), 625-631. 
Gómez, M.-Á., DelaSerna, A., Lupo, C., \& Sampaio, J. (2014). Effects of situational variables and starting quarter score in the outcome of elite women's water polo game quarters. International Journal of Performance Analysis in Sport, 14(1), 73-83.

Gómez, M.-Á., Gasperi, L., \& Lupo, C. (2016). Performance analysis of game dynamics during the 4th game quarter of NBA close games. International Journal of Performance Analysis in Sport, 16(1), 249-263.

Gómez, M.-Á., Serna, A. D., Lupo, C., \& Sampaio, J. E. (2016). Effects of game location, quality of opposition, and starting quarter score in the outcome of elite water polo quarters. The Journal of Strength \& Conditioning Research, 30(4), 1014-1020.

Grant, A., Williams, A., Reilly, T., \& Borrie, T. (1999). Analysis of the goals scored in the 1998 world cup. Journal of Sports Sciences, 17(10), 826-827.

Harrop, K., \& Nevill, A. (2014). Performance indicators that predict success in an english professional league one soccer team. International Journal of Performance Analysis in Sport, 14(3), 907-920.

Hoppe, M., Slomka, M., Baumgart, C., Weber, H., \& Freiwald, J. (2015). Match running performance and success across a season in German bundesliga soccer teams. International Journal of Sports Medicine, 36(07), 563-566.

Hughes, M. D., \& Bartlett, R. M. (2002). The use of performance indicators in performance analysis. Journal of Sports Sciences, 20(10), 739-754.

Kite, C. S., \& Nevill, A. (2017). The predictors and determinants of inter-seasonal success in a professional soccer team. Journal of Human Kinetics, 58(1), 157-167.

Lago, C., \& Martín, R. (2007). Determinants of possession of the ball in soccer. Journal of Sports Sciences, 25(9), 969-974.

Lago-Penas, C., \& Lago-Ballesteros, J. (2011). Game location and team quality effects on performance profiles in professional soccer. Journal of Sports Science \& Medicine, 10(3), 465-471. Retrieved from http://www.ncbi.nlm.nih.gov/pubmed/24150619

Lago-Peñas, C., Lago-Ballesteros, J., Dellal, A., \& Gómez, M. (2010). Game-related statistics that discriminated winning, drawing and losing teams from the Spanish soccer league. Journal of Sports Science \& Medicine, 9(2), 288.

Lago-Peñas, C., Lago-Ballesteros, J., \& Rey, E. (2011). Differences in performance indicators between winning and losing teams in the UEFA champions league. Journal of Human Kinetics, 27, 135-146.

Liu, H., Gomez, M. A., Lago-Penas, C., \& Sampaio, J. (2015). Match statistics related to winning in the group stage of 2014 Brazil FIFA world cup. Journal of Sports Sciences, 33(12), 12051213. Retrieved from http://www.ncbi.nlm.nih.gov/pubmed/25793661.

Liu, H., Hopkins, W. G., \& Gomez, M. A. (2016). Modelling relationships between match events and match outcome in elite football. European Journal Sport Sciences, 16(5), 516-525. Retrieved from http://www.ncbi.nlm.nih.gov/pubmed/26190577.

Mao, L., Peng, Z., Liu, H., \& Gómez, M.-A. (2016). Identifying keys to win in the Chinese professional soccer league. International Journal of Performance Analysis in Sport, 16(3), 935947.

Moura, F. A., Martins, L. E. B., Anido, R. O., Ruffino, P. R. C., Barros, R. M., \& Cunha, S. A. (2013). A spectral analysis of team dynamics and tactics in Brazilian football. Journal of Sports Sciences, 31(14), 1568-1577.

Ntoumanis, N. (2001). A step-by-step guide to SPSS for sport and exercise studies. London: Routledge.

O’Donoghue, P. (2005). Normative profiles of sports performance. International Journal of Performance Analysis in Sport, 5(1), 104-119.

Rampinini, E., Impellizzeri, F. M., Castagna, C., Coutts, A. J., \& Wisloff, U. (2009). Technical performance during soccer matches of the Italian Serie A league: Effect of fatigue and competitive level. Journal of Science and Medicine in Sport / Sports Medicine Australia, 12 (1), 227-233. . Retrieved from http://www.ncbi.nlm.nih.gov/pubmed/18083631. 
Szwarc, A. (2004). Effectiveness of Brazilian and German teams and the teams defeated by them during the 17th FIFA world cup. Kinesiology: International journal of fundamental and applied kinesiology, 36(1), 83-89.

Tabachnick, B. G., Fidell, L. S., \& Osterlind, S. J. (2001). Using multivariate statistics: Allyn \& Bacon/Pearson Education. Kinesiology: International journal of fundamental and applied kinesiology, 36(1), 83-89.

Taylor, B. J., Mellalieu, D. S., James, N., \& Barter, P. (2010). Situation variable effects and tactical performance in professional association football. International Journal of Performance Analysis in Sport, 10(3), 255-269.

Taylor, J. B., Mellalieu, S. D., James, N., \& Shearer, D. A. (2008). The influence of match location, quality of opposition, and match status on technical performance in professional association football. Journal of Sports Sciences, 26(9), 885-895. Retrieved from http://www.ncbi.nlm.nih. gov/pubmed/18569554.

Yang, G., Leicht, A. S., Lago, C., \& Gómez, M.-Á. (2018). Key team physical and technical performance indicators indicative of team quality in the soccer Chinese super league. Research in Sports Medicine, 26(2), 158-167.

Yue, Z., Broich, H., \& Mester, J. (2014). Statistical analysis for the soccer matches of the first Bundesliga. International Journal of Sports Science \& Coaching, 9(3), 553-560.

Zubillaga, A., Gorospe, G., Mendo, A., \& Villaseñor, A. (2007). Match analysis of 2005-06 champions league final with amisco system. Journal of Sports Science \& Medicine, 6(10), 20. 